Revista General de Información y Documentación ISSN: 1132-1873

http://dx.doi.org/10.5209/RGID.56560

\title{
Epistolarios digitales: la adaptación de la carta al escenario digital
}

\author{
Virginia Ramírez Martín ${ }^{1}$
}

Recibido: 8 de octubre 2016 / Aceptado: 20 de diciembre de 2016

Resumen. El valor científico de los epistolarios se ha revelado desde hace décadas como esencial para el avance en muy diversas disciplinas, así como una herramienta determinante para la reconstrucción de la intrahistoria de cualquier época. Sin embargo, el presente plantea varios problemas al respecto de este tipo de colecciones documentales, en plena transición al escenario digital y algunas de ellas ya plenamente mudadas. No solo se han diversificado enormemente, como consecuencia del desarrollo tecnológico y también del cambio sustancial sufrido por los fenómenos comunicativos, sino que plantean numerosas incógnitas en lo que a su conservación y tratamiento archivístico se refiere. El presente artículo pretende acercarse a la complejidad de estos materiales y resaltar su inestimable valor para las futuras investigaciones.

Palabras clave: Cartas; Archivos personales; Fuentes de información científica; Documentos digitales.

\section{[en] Digital collected letters: the transformation of letters to digital environment}

\begin{abstract}
From several decades ago, the scientific value of collected letters has revealed itself as an essential piece to progress in several fields of research, as well as a key tool to rebuilt its inner-history in every time. However, the present situation poses several problems in relation with this type of document collection, both documents in the middle of transition to digital stage and some of them changed thoroughly. Not only they have been diversified themselves hugely in consequence of technologic development and essential change suffered from tool for communicating, but also they pose a lot of doubts about its preservation and treatment. The present article tries to get closer to complexity of these materials and highlights their inestimable value from future research is yet to come.
\end{abstract}

Keywords: Letters; Personal archives; Scientific information resources; Digital documents.

Sumario. 1. Introducción. 2. Los epistolarios digitales: ¿Las mismas cartas con distinto soporte? 3. Tratamiento y conservación de los epistolarios digitales. 4. La necesidad de una estrategia. 5. A modo de colofón. 6. Referencias bibliográficas.

Cómo citar: Ramírez Martín, V. (2017) Epistolarios digitales: la adaptación de la carta al escenario digital, en Revista General de Información y Documentación 27 (1), 25-44.

1 Archivo del Congreso de los Diputados

E-mail: virginia.ramirez@congreso.es 
Guardé tus cartas en la arquilla de mis joyas. Releerlas de noche era mi delicia, pero también era una imprudencia

Anatole France, La azucena roja

\section{Introducción}

Los epistolarios constituyen una fuente de información de primer orden para varias disciplinas, pues estas colecciones de misivas ofrecen datos de inestimable valor para el conocimiento de extremos enormemente diversos. Así, gracias a estas cartas se ha conocido la evolución de experimentos científicos, los avatares de la creación literaria, las relaciones entre miembros de grupos o generaciones ${ }^{2}$, conexiones personales $^{3}$, y se podrían poner otros muchos ejemplos. Pues bien, el valor de su contenido pone de relieve la enorme significación de estos grupos documentales para una gran cantidad de fines en relación con la investigación de diversas especialidades, entre las que destacan de forma muy significativa las ciencias humanas y sociales.

Es, pues, en el ámbito de la investigación humanística y social que las cartas que constituyen los epistolarios han desempeñado quizá el papel más importante, abriendo nuevos caminos y sugiriendo otras hipótesis sobre las que avanzar, tanto que han de ser consideradas una fuente de información de primer orden.

Las cartas, por otra parte, son un tipo de documentación que, a pesar de que cumple de modo genérico el objetivo de transmisión de un mensaje entre quien remite y quien recibe el documento, entre quien la escribe y su destinatario, cuenta con una enorme diversidad en lo que a la temática y, sobre todo, a la tipología de los que intercambian las misivas se refiere. Existe la correspondencia diplomática, las cartas políticas, las epístolas literarias, las cartas públicas y privadas, hasta son un género literario para el que existen reglas y prescripciones de estilo. Es tal la importancia de la epístola como vehículo para la comunicación que ya en la Edad

2 Buena muestra de ello puede ser la compilación Queridos todos. El intercambio epistolar entre escritores hispanoamericanos y españoles del siglo XX (Gallego y Martínez, 2013). Esta obra abunda en la idea de que la literatura se nutre del diálogo, y la carta ha sido en buena medida el vínculo que ha hecho florecer el diálogo entre escritores a veces muy distantes pero unidos por la palabra, la lengua y la literatura.

3 Un claro ejemplo del modo en el que las cartas pueden ayudar a reconstruir el devenir de una relación son los intercambios epistolares entre Hannah Arendt y Gershom Scholem. Ambos son admiradores de Walter Benjamin y herederos de la tradición intelectual centroeuropea, aunque los dos habían desarrollado sus carreras en otros lugares, Estados Unidos e Israel respectivamente, pero es el vínculo de Benjamin lo que les une cuando se conocen en Berlín en 1932. Arendt escribe después a Scholem para comunicarle el suicidio de Walter Benjamin en 1940 y desde ese momento la relación epistolar entre ellos se hace regular, llegando a recoger estas cartas mucho del pensamiento de ambos al respecto de asuntos muy diversos. El contenido de estas cartas ha merecido una gran atención por parte del mundo editorial, bien de forma selectiva o completa, en varios idiomas. Véase, entre otros, Knott, 2010, obra en la que se edita la correspondencia habida entre ambos desde 1939 hasta 1964, aunque muchas de estas cartas ya habían sido publicadas de manera fragmentaria en otras obras sobre la pensadora y el investigador especialista en cábala y tradición judía. A partir de sus colecciones de cartas respectivas y no solo las que ellos intercambian, pues los dos mantienen intensas relaciones epistolares con grandes figuras intelectuales contemporáneas, es posible reconstruir un universo de relaciones a propósito de intereses comunes. 
Media se establecen diversos ensayos de una tipología epistolar dependiendo de su finalidad, y se busca la definición de una carta-tipo según sus diversas partes (Martín Baños, 2009: 141-178).

La epistolografía, en términos generales la actividad consistente en la escritura de cartas, se ha visto considerada dentro del campo de la literatura, casi como un género literario más. Así lo desarrolla Trinidad Arcos al trazar la evolución de la epistolografia desde Roma y hasta el siglo XV (Arcos, 2008). La autora destaca que, frente a los grandes géneros literarios, en el mundo clásico no es hasta época tardía que la carta recibe tratamiento diferenciado en su aspecto formal, a pesar de que el envío de cartas es una práctica ya asentada. En Roma ya hay testimonios de cartas privadas, y a este conjunto pertenecen los intercambios epistolares de Cicerón, quien ya define la carta como "conversación de amigos ausentes" (Arcos, 2008: 351). El género literario que constituyen las cartas es un género de enorme flexibilidad, para el que las prescripciones o los corsés llegan más tarde, a medida que se desarrolla una preceptiva sistematizada. Y esto no deja de avanzar hasta que es el propio Erasmo de Rotterdam el que acaba por dar cuerpo a la teoría epistolar humanística, que no se ciñe solo a la carta familiar o privada, sino que se acaba por extender también a la epístola oficial, llegando a proponer fórmulas y consejos apropiados para la tarea de la redacción epistolar.

Es una evidencia, por lo tanto, que estos documentos han desempeñado, más allá del valor que hoy se les pueda atribuir en el campo de la investigación científica o en el ámbito literario, funciones muy diversas a lo largo de la Historia, pero vinculadas inequívocamente con la comunicación.

A pesar de la enorme cantidad de vestigios y testimonios que para la investigación histórica ha supuesto la conservación de las cartas a través de los siglos, no es hasta épocas muy recientes que se ha llevado a cabo una investigación sistemática a partir de estos documentos. Sin embargo, su importancia para otro tipo de fines está respaldada por el esfuerzo de recopilación y conservación que de las cartas, sobre todo de algunos tipos de ellas, se hace en los archivos. Es este, entre otros, el caso del Archivo Secreto Vaticano y otros grandes archivos de Estado, que muy pronto tomaron conciencia de la necesidad de conservar estas misivas, pues entre sus líneas se encontraba valiosísima información política.

Hoy los correos electrónicos son su reflejo contemporáneo y también en ellos se registra información política muy significativa. Sirva como ejemplo la reciente desclasificación por parte del Departamento de Estado de los Estados Unidos de cerca de 300 correos electrónicos de Hillary Clinton que fueron recopilados bajo su mandato como Secretaria de Estado y en los que se intercambia valiosa información acerca de un ataque acontecido en Bengasi contra la Embajada de Estados Unidos acontecido el 11 de septiembre de $2012^{4}$.

4 Véase la noticia publicada en El País en su edición digital con fecha 22 de mayo de 2015, disponible en $<$ http://internacional.elpais.com/internacional/2015/05/22/actualidad/1432326016_365288.html >, [consulta: 03/07/2016]. Los documentos desclasificados se encuentran en el sitio web del Departamento de Estado de los Estadios Unidos, cuya búsqueda se puede llevar a cabo a través del enlace $<$ http://foia.state.gov/Search/Search.aspx>, [consulta: 06/07/2016]. 
Son muchos los autores que han reflexionado sobre el valor científico de este tipo de documentos (Mestre Sanchís, 2000), las cartas, y lo cierto es que esta documentación se ha convertido en un auxiliar imprescindible para la investigación científica de carácter multidisciplinar. La escuela de Lucien Febvre es, en buena medida, responsable de la generalización del uso de los epistolarios como fuente de información científica, primero para el contexto de la investigación histórica e historiográfica, y después para otras muchas disciplinas. Entre ellas, destaca el uso hecho por la investigación literaria de este género, tanto es así que los repertorios de cartas se han incorporado, en muchos casos, a la producción literaria de diversos autores y hoy se consideran indispensables en el caso de algunos autores, sobre todo durante el siglo XX, para alcanzar a comprender su obra, llegando a ser considerados incluso parte de ella.

Es, pues, gracias a la Escuela de los Annales que se amplían los límites de lo que hasta entonces se había empleado como instrumento de la Historia. Tanto es así que Marc Bloch llega a afirmar que "[...] La diversidad de los testimonios históricos es casi infinita. Todo lo que el hombre dice o escribe, todo lo que fabrica, todo cuanto toca, puede y debe informarnos acerca de él" (Salmon, 1978: 39). Pues bien, la influencia de esta nueva forma de aproximación a la Historia muy pronto logró calar en la metodología de la investigación de otras muchas ciencias, debido este hecho también en buena medida a la progresiva difuminación de los límites inter-ciencias que propicia el carácter multidisciplinar de la investigación contemporánea.

A pesar de que, según la terminología archivística, este tipo de documentos han formado, y lo siguen haciendo, parte de los denominados archivos personales ${ }^{5}$, la investigación más reciente está descubriendo conjuntos documentales epistolares dentro de archivos institucionales, y a veces incluso abandonados en terreno de nadie por no haber sido reclamados por la familia a la muerte de la persona que los creó y no haber sido considerados propios por la institución a la que esta persona pertenecía. Se trata de conjuntos de misivas e intercambios epistolares que se recopilan a lo largo de la trayectoria o el desempeño profesional de alguien; generalmente se trata de una persona con un cargo representativo o amplio reconocimiento en su ámbito profesional, en cuyas cartas se deslizan, no obstante, pinceladas personales. Este es el caso, entre otros muchos, de los epistolarios de Julián Ribera Tarragó y Miguel Asín Palacios (Marín et. al., 2009), que proceden de la antigua Escuela de Estudios Árabes de Madrid y que son descubiertos en 1999. Se trata, pues, de un fondo documental perteneciente a una institución y que recoge los intercambios epistolares profesionales de dos grandes figuras del arabismo español, en el que también es posible vislumbrar mucho de su personalidad y de las relaciones personales que crecen a la sombra de los vínculos generados por su desempeño profesional.

Pons Alós define los archivos personales como "aquellos que agrupan la documentación relacionada con el o los cargos ocupados por un importante personaje y su trayectoria cultural, eclesiástica, social o económica" (Pons Alós, 1996), resaltando la indisolubilidad de la trayectoria personal y el desempeño profesional para la constitución de estos conjuntos documentales. 
Este asunto, su carácter público o privado, es un elemento decisivo a la hora de determinar asuntos como el régimen de acceso a los fondos, su integración o no en la consideración de patrimonio documental, así como en la obligatoriedad o no, en consecuencia, de garantizar su conservación, protección o difusión, en virtud de lo establecido por la Ley del Patrimonio Histórico Español ${ }^{6}$.

También desde el ámbito de la archivística las colecciones de cartas están suscitando un interés creciente. Buena muestra de ello son las Jornadas Archivo y Memoria, cuya quinta edición fue celebrada en 2011 bajo el título Extraordinarios y fuera de serie: formación, conservación y gestión de archivos personales y se dedicó íntegramente a los problemas de concepto y de método que este tipo de documentos plantean ${ }^{7}$. Ya desde su denominación estas jornadas llevaron a destacar una de las características fundamentales de este tipo de fondos: su carácter extraordinario. Este es también uno de los rasgos de cualquier documento de archivo, sin embargo, en el caso de los documentos que forman parte de los archivos personales, esta característica se exacerba, pues la multiplicidad de matices de la información que transmite hace que sea casi inmediato tomar conciencia de su unicidad. O, como resumen Antonia Salvador y Antonio Ruíz, "los archivos personales acogen testimonios e información de facetas muy variadas del hombre [...] muy difíciles de apreciar en otro tipo de fondos" (Salvador Benítez y Ruiz Rodríguez, 2011).

Normalmente los epistolarios contribuyen a dar volumen al relato de su autor, dando valiosas pistas acerca de su personalidad, sus intereses, sus relaciones personales y profesionales. En definitiva, "las cartas se convierten fácilmente en puertas francas que permiten acceder al alma de los corresponsales" (Rubio Jiménez y Deaño Gamillo, 2011: 9). Por tal motivo, las colecciones de cartas se mueven entre lo profesional y los asuntos privados, resultando, en consecuencia, difícil deslindar los dos ámbitos que constituyen la vida de quien las firma y más difícil aún describir su contenido ${ }^{8}$.

Carme Figuerola, recurriendo al análisis formulado por Mireille Bossis, señala que la carta, y el epistolario como conjunto, tiene un carácter ambiguo que está condicionado por sus cuatro dimensiones: documento como objeto "auténtico", o personal, que deja traslucir la esfera privada del individuo; como objeto de escritura y, en consecuencia, interpretación subjetiva de los acontecimientos; como discurso, que deja entrever o muestra por completo el imaginario de una época; y, por último, como instrumento de comunicación (Figuerola, 2002: 197).

Superada, pues, la fase de la toma de conciencia de la importancia que entrañan estos conjuntos documentales para la nueva ciencia y para otros fines diversos se han puesto en marcha muchos proyectos para la utilización y difusión intensivas de

Ley 16/1985, de 25 de junio, del Patrimonio Histórico Español, art. 36 y 52.

Todas las comunicaciones presentadas en las V Jornadas Archivo y Memoria. Extraordinarios y fuera de serie: formación, conservación y gestión de archivos personales, se pueden consultar en la dirección web $<$ http://www.archivoymemoria.com/jornada_05/comunicaciones_05.htm>, [consulta: 03/07/2016].

8 Para profundizar sobre esta dimensión de las epístolas y su aplicación a un epistolario concreto, el de Zenobia Camprubí, véase un artículo de Emilia Cortés cuyo título me parece enormemente revelador: "El epistolario, espejo de la intrahistoria" (Cortés, 2010). 
ellos. Por una parte, la archivística ha dirigido algunos de sus esfuerzos en la dirección de la normalización de la gestión y tratamiento de los archivos personales $\mathrm{y}$, dentro de estos, de los conjuntos epistolares. Y por otra parte, desde diversas ciencias se ha auspiciado su difusión, ya sea mediante su edición tradicional o digital, tras la indispensable digitalización y puesta a disposición pública. Uno de los proyectos más ambiciosos en este ámbito es el proyecto Epístola, cuyo objeto es la edición digital de los epistolarios de la Edad de Plata, habida cuenta de que estos documentos son fundamentales para el estudio del período 1898-1936 (González García, 2014).

Sin embargo, la condición fundamental para poder disponer de este tipo de documentos es que se hayan conservado. Y su conservación, a lo largo de los siglos, revela la existencia de voluntad al respecto. La voluntad de su receptor primero, que ha conservado durante, en no pocas ocasiones, toda una vida, las cartas que ha ido recibiendo; y no sólo las ha conservado, sino que a veces las ha llegado a clasificar u organizar de algún modo hasta formar su archivo personal. Por otra parte, ha confluido en otros casos la voluntad de la familia, de la institución para la que trabajó o, en otros casos fundaciones constituidas al calor de estas figuras, para reunir estas colecciones a la muerte de quien las generó ${ }^{9}$, siendo en la mayor parte de los casos personas de relevancia en diversos terrenos. Sin embargo, y aunque esta afirmación no resulte demasiado ortodoxa, interviene en un número de casos relativamente elevado de forma muy decisiva la suerte, ya sea en lo que tiene que ver con su conservación o respecto del acceso que los investigadores puedan tener a aquellos materiales ${ }^{10}$.

Por otra parte, el apego a la palabra escrita, inserto desde hace siglos en la conciencia de la sociedad, ha dado como resultado la conformación de muchas colecciones de documentos personales, entre los que las cartas ocupan un lugar muy destacado como consecuencia, seguramente, de la conversión de la escritura de cartas en un ejercicio cotidiano (Castillo, 2002: 81).

Y esta incorporación de la carta a la cotidianidad se mantiene inalterable en muchos sentidos hasta el momento en el que irrumpen las nuevas tecnologías,

9 Aunque aquí se podrían citar otros muchos ejemplos, conviene traer a colación dos conjuntos epistolares de singular relevancia, como son los de Camilo José Cela y Miguel Delibes. La Fundación Camilo José Cela indica en la descripción del fondo documental constituido por estas cartas que son más de 95.000 intercambiadas con 13.000 personalidades distintas; tal es su importancia que "esta magnífica colección es imprescindible para la investigación de la cultura española de posguerra". El archivo de la Fundación Miguel Delibes, por su parte, reúne "los documentos generados o reunidos por Miguel Delibes a lo largo de su vida, incluyendo, lógicamente, los que corresponden a su tarea profesional". Entre ellos se encuentran multitud de cartas a las que, a través de la navegación por su cuadro de clasificación, se puede acceder al documento en muchos casos y, en otros, a la descripción archivística. Estas cartas son también muy diversas, pues son intercambiadas con su editor, cartas de felicitación recibidas a propósito de sus diversas menciones y honores (premios, ingreso en la Real Academia Española, etc.), intercambios con otros escritores y críticos literarios, investigación sobre la procedencia del apellido Setién... La digitalización, así como la previa labor de identificación, organización y descripción se encuentran disponibles en el sitio web del Archivo Miguel Delibes: <http://fondomigueldelibes.fundacionmigueldelibes.es/index.php/>, [consulta: 05/07/2016].

10 Sirva como muestra de uno de estos azarosos casos el que expone Pedro Ignacio López García. El autor explica con detalle cómo pudo acceder a la consulta de un heterogéneo "archivo" custodiado en un "armario metálico de un piso trasero [...] propiedad de los dueños de Casa Ciriaco" en el que se conservaba una colección de cartas dirigidas algunas y remitidas otras por Julio Camba (López, 2007: 137-139) 
transformando para siempre la concepción de los límites de la transmisión de la información y los intercambios comunicativos.

Así, pues, y habida cuenta de la mutación que nuestra realidad está sufriendo en plena mudanza hacia un paradigma digital de transmisión y gestión de la información, se plantea cómo habrá de ser, o como debería estar siendo ya, la conservación, recopilación y tratamiento de este tipo de documentos en el escenario digital, partiendo de la plena conciencia de que han sido uno de los primeros tipos documentales en migrar de forma masiva hacia otro tipo de soportes.

\section{Los epistolarios digitales: ¿Las mismas cartas con distinto soporte?}

Auspiciados por el nuevo escenario social que se dibuja ya en el último cuarto del siglo pasado tienen lugar diversos fenómenos que contribuyen también a marcar el paso de las sociedades contemporáneas. Entre otros, la globalización, la interdependencia de las sociedades, la crisis del capitalismo y la revolución tecnológica se pueden considerar, a un tiempo, causa y consecuencia del cambio; matriz y resultado en un proceso de intrincadas implicaciones que no permite deslindar por completo los acontecimientos que trazan el devenir de esta nueva era.

Tomados en conjunto, rasgos muy diversos constituyen hoy la base material del patrón social, económico y cultural que define la realidad presente, caracterizada por el asentamiento de la sociedad en el cambio permanente. Este proceso de transformación se encuentra jalonado por los cambios que han sacudido en cadena todos los ámbitos de la actuación humana, a saber: las relaciones humanas, las relaciones sociales, la administración pública, los procesos de toma de decisiones, el acercamiento a la información, la participación política, los medios de comunicación y, de forma muy significativa, los hábitos y formas de comunicación humana ${ }^{11}$. En definitiva, no hay actuación social del ser humano que haya escapado a este terremoto que es el nuevo modelo de sociedad.

El nuevo contexto informacional y tecnológico en el que se desenvuelven las sociedades contemporáneas ha influido de forma muy notable en la transformación de los hábitos de comunicación ${ }^{12}$, desarrollando, según el pensamiento de Manuel Castells, la convivencia de tres formas o tipos de comunicación: "interpersonal,

11 Sirva como ejemplo, aunque es ya incontable la bibliografía que pretende afrontar la significación de los fenómenos indicados, de estas transformaciones el análisis de las repercusiones del nuevo paradigma social un artículo de Carlos Elías publicado en la revista Arbor que aborda la influencia de la cultura 2.0 en los medios de comunicación y en la comunicación científica a raíz de la teoría de la cultura convergente de Jenkins y la irrupción del fenómeno conocido como "dictadura de las audiencias" en la cadena de la transmisión de la información científica (Elías, 2009). Esta transformación sufrida por un tipo muy concreto de comunicación puede servir como ejemplo de las profundas modificaciones que la comunicación, en todos sus tipos y vertientes, viene sufriendo desde la irrupción de las TIC.

12 Para un análisis de la transformación sufrida por la comunicación en las últimas décadas véase Castells, 2009. El autor señala que a las puertas del tercer milenio la comunicación tiene un carácter más dinámico y multidireccional, al tiempo que están teniendo lugar también fenómenos nuevos, como sucede con la "autocomunicación de masas", desarrollada al socaire de la viralidad de Internet. 
comunicación de masas y autocomunicación en masa, que coexisten, interactúan, y más que sustituirse se complementan entre sí" (Castells, 2009: 88).

El presente, pues, traza un escenario enormemente complejo y heterogéneo en lo que a la comunicación se refiere. Antonio Rodríguez de las Heras concreta las claves de esta "migración digital"13, al tiempo que hace constar un principio de enorme importancia: la Sociedad de la Información, este nuevo escenario en el que se está desenvolviendo la contemporaneidad, "no es un estado, sino un proceso" que sólo se colmará cuando termine esta migración que al mundo o la realidad digital se está produciendo (Rodríguez de las Heras, 2004). Y esta traslación digital está logrando ya que actividades que anteriormente se desenvolvían en un "escenario analógico", se estén mudando progresiva o íntegramente a la dimensión digital.

Así está sucediendo, en buena medida, con una gran parte de las comunicaciones humanas. Las herramientas tecnológicas están contribuyendo a diversificar enormemente el panorama de la comunicación: correos electrónicos, chats, sms, whattsapp, redes sociales, entradas en blogs... Todos ellos se basan en el intercambio de mensajes escritos entre un emisor y un receptor, a veces un receptor múltiple y hasta desconocido, si bien el carácter diferido de la comunicación, rasgo definitorio de la comunicación epistolar, se está desdibujando notablemente, pues una de las notas características de todos ellos es la creciente ruptura de las barreras que el tiempo y el espacio marcaban para la comunicación, logrando que estos mensajes viajen en unos pocos segundos, y a veces de forma inmediata, entre dos o más personas a las que en muchos casos separa una gran distancia.

Hoy el tipo de comunicación que desde hace siglos se venía estableciendo a través de las cartas se ha visto irremediablemente remplazada por este tipo de intercambios de carácter multiforme y que, sin embargo, cumplen en lo fundamental el objeto que antes era patrimonio de las misivas: el establecimiento de vínculos comunicativos entre los corresponsales hasta convertir la carta en casi un uso residual asociado en su mayor porcentaje a la correspondencia de carácter comercial y la de carácter oficial.

Estas profundas e interesantes transformaciones habidas en el entorno informacional dan cuenta de que en lo que se refiere a la transposición de las cartas a este nuevo contexto se ha producido algo más que un simple cambio de soporte. Se han modificado de forma muy profunda los hábitos comunicativos y las necesidades experimentadas por los actores del proceso de la comunicación, por lo que los medios a través de los que ésta se establece han mutado consecuentemente, al mismo tiempo que las herramientas tecnológicas han contribuido, a veces como causa y otras como consecuencia, de forma decisiva en este acontecimiento.

No obstante, es el correo electrónico quizá el heredero natural y contemporáneo de las cartas, pues no sólo es la aplicación más utilizada y generalizada de la Web,

13 El profesor Rodríguez de las Heras plantea que la migración digital está teniendo lugar en torno a tres pautas o claves, a saber: la dualidad, dada la convivencia, desigual en ocasiones, de los escenarios digital y analógico; la brecha o brechas abiertas en función de esta migración, que compara en este sentido con otros movimientos migratorios habidos en la Historia y las desigualdades sociales y económicas generadas en consecuencia; y la crisis, que ha empujado en cierto sentido a adoptar esta realidad como único mecanismo válido para salir de ella (Rodríguez de las Heras, 2004). 
sino que su uso se ha extendido también a las instituciones, sustituyendo $u$ ocupando, en exclusiva incluso, el espacio reservado anteriormente para las comunicaciones postales o a través del fax. Sirva como ejemplo de este extremo la implantación de las comunicaciones a través del correo electrónico como medio preferente de comunicación interna y con los ciudadanos en el Ayuntamiento de Madrid $^{14}$, así como los avances que en materia de Administración Electrónica se están llevando a cabo desde la Administración General del Estado y las Administraciones de las Comunidades Autónomas ${ }^{15}$. Tanto es así, que la Ley 39/2015, de 1 de octubre, del Procedimiento Administrativo Común de las Administraciones Públicas, que acaba de entrar en vigor, viene a reconocer que, en el entorno actual, "la tramitación electrónica no puede ser todavía una forma especial de gestión de los procedimientos sino que debo constituir la actuación habitual de las Administraciones"16.

En lo que respecta de forma concreta al correo electrónico, el grupo de trabajo de Documentos electrónicos de la Conferencia de Archiveros en las Universidades Españolas (CAU-CRUE) ya alerta sobre la ambigüedad del término, que alude a tres realidades: al medio, a la herramienta y al propio mensaje. Esta falta de univocidad ya determina en algún sentido la falta de acercamientos integrales al tratamiento de la documentación epistolar digital, habida cuenta además de que, en lo que tiene que ver con las relaciones establecidas por este medio entre las Administraciones Públicas y los ciudadanos, este tipo de comunicaciones son susceptibles de reemplazar otro tipo de comunicaciones e, incluso, formar parte de los procedimientos administrativos, momento en el que su conservación, además de una garantía para el ciudadano, es una exigencia determinada por la ley ${ }^{17}$.

Un correo electrónico puede ser, a todos los efectos, un documento con validez jurídica plena, en el caso de que cumpla los requisitos o las condiciones establecidas en los artículos 29 a 32 de la Ley 11/2007, de acceso de los ciudadanos a los servicios electrónicos. Sin embargo, por este y otros medios las Administraciones Públicas trasladan información a los ciudadanos, como sucede, por ejemplo, cuando se envía un sms a través del que se comunica la publicación de una resolución o bien se remite un correo electrónico con el mismo fin en una multiplicidad de casos. Así, pues, estos mensajes de texto y correos electrónicos sustituyen a la carta que se le remitiría con este mismo fin, constituyendo otro ejemplo más de cómo en el ámbito de las Administraciones Públicas la transición al mundo digital es también ya imparable.

14 Decreto de 18 de febrero de 2013 de la Delegada de Área de Gobierno de Economía, Hacienda y Administración Pública por la que se aprueba la Instrucción 2/2013 relativa a la implantación del correo electrónico como medio de comunicación interna y con los ciudadanos (BOAM de 25 de febrero de 2013).

15 El OBSAE, Observatorio de Administración Electrónica, dispone de varios informes y estudios relacionados con la implantación y el avance de la Administración Electrónica en España, a los que se puede acceder a través de su página web: <http://administracionelectronica.gob.es/pae_Home/pae_OBSAE.html\#. UfDV1WXFY9Q> [consulta: 03/07/2016].

16 Preámbulo de la Ley 39/2015, de 1 de octubre, del Procedimiento Administrativo Común de las Administraciones Públicas.

17 Sobre la consideración de documento en la Administración electrónica y sus implicaciones, vid. Feijoo, 2009, p. 164-165. Para un análisis de la realidad de la Administración electrónica y los retos que plantea desde el punto de vista de la archivística, véase Feijoo, 2009. 
Esta correspondencia oficial, que no es stricto sensu parte de un procedimiento, a pesar de su enorme importancia y, sobre todo, de ser uno de los aspectos de la Administración Electrónica cuyo tratamiento desde el punto de vista de los archiveros está aún pendiente de desarrollo ${ }^{18}$, logrará finalmente una solución, pues por ella pasa una parte muy importante del flujo de comunicación, tanto interna como externa, de la Administración en el presente.

A este respecto la Conferencia de Archiveros en las Universidades Españolas ha formulado una propuesta proyectada para el tratamiento de este tipo de documentos en las Universidades, dentro de la que se contemplan diversas orientaciones prácticas pero, sobre todo, se incorpora el método archivístico como principio de actuación, siendo esto último lo esencial, en mi opinión, de la propuesta, pues se repara en la necesidad de considerar a todos los efectos los correos electrónicos como documentos en el sentido archivístico del término ${ }^{19}$, sujetos, por lo tanto, al tratamiento que para ellos dispone la ciencia archivística.

$\mathrm{Y}$ es que, como se ha tratado de evidenciar en los párrafos precedentes, existen diferentes conjuntos documentales que pueden ser identificados con las cartas (oficiales, comerciales, personales, con valor literario o susceptibles de desarrollar valores históricos...), que responden también a finalidades comunicativas diversas, por lo que, más allá de cuestiones legales y otras relativas al tipo de soporte o la tecnología con la que hayan sido generadas, deben necesariamente tratarse desde el prisma archivístico de forma diferente también, desarrollando tratamientos ad hoc para su preservación y acceso.

Dejando al margen esta diversidad que es intrínseca a la correspondencia y los conjuntos de comunicaciones de carácter oficial, el presente artículo pretende abordar cuestiones relativas a la conservación y el tratamiento que desde el punto de vista archivístico han de recibir las comunicaciones de carácter privado o personal establecidas por medios digitales y que posiblemente conformarán los epistolarios del futuro, los epistolarios digitales, susceptibles de convertirse en las fuentes de información histórica, literaria, científica, sociológica, y casi de cualquier orden que permitan el desarrollo de la investigación que en todas estas parcelas del conocimiento está por venir.

\section{Tratamiento y conservación de los epistolarios digitales}

La atención profesional se ha dirigido hasta la fecha al control archivístico y al diseño de planes de conservación para la documentación generada en el seno de las

18 Un artículo de Julio Cerdá hace balance de los primeros años desde la entrada en vigor de la Ley 11/2007 en el ámbito de la Administración Local y destaca que una de las realidades de su implantación es que se está aprendiendo sobre la marcha, es decir, que las estrategias se están desarrollando de forma simultánea al desarrollo de este nuevo modelo de relación de la Administración, por lo que muchas soluciones archivísticas están aún pendientes (Cerdá, 2013).

19 Véase la Propuesta de Recomendaciones para la gestión y conservación del correo electrónico en las Universidades españolas, formulada en 2010 por el Grupo de Trabajo de Política de Gestión de documentos electrónicos y cuyo texto se encuentra disponible en <http://cau.crue.org/export/sites/Cau/Quehacemos/ gruposdetrabajo/documentoselectronicos/recomendaciones_correo.pdf $>$, [consulta: 03/07/2016]. 
organizaciones. Sin embargo, los documentos generados por los individuos, los que son susceptibles de constituir los archivos personales, han recibido escasa atención hasta el momento, si bien algunas de las premisas generales para la gestión documental de las organizaciones puede adoptarse como solución, al menos parcial, para los documentos personales. Se pueden, pues, asumir algunas de las propuestas recogidas en Digital records preservation: Where to Start Guide, publicada en 2010 por el Grupo de trabajo ISO que se ocupa de conservación de documentos digitales, así como las orientaciones generales contempladas en las normas ISO redactadas a este efecto.

La realidad de las comunicaciones en el presente está contribuyendo a complicar y diversificar más aún el panorama. Muchas de las manifestaciones o intercambios comunicativos no son ni siquiera considerados por su emisor o su receptor como tales. Esta informalidad asociada al mensaje escrito hace que este tipo de documentos digitales se encuentren en los márgenes de la consideración de documento $\mathrm{y}$, por lo tanto, no se encuentran contemplados de manera expresa en la pocas y fragmentarias propuestas que desde el ámbito de la Archivística se han impulsado.

El grupo de trabajo de documentos electrónicos, constituido en el seno de la citada Conferencia de Archiveros en las Universidades Españolas y dependiente de la $\mathrm{CRUE}^{20}$ propuso una aproximación al tratamiento de los correos electrónicos en el ámbito universitario cuya principal aportación, como antes se indicaba, es la aplicación del método archivístico para este tipo de fines. Asimismo, la publicación en 2011 en la sección "Temas" de la revista Archivamos, publicada por la Asociación de Archiveros de Castilla y León del monográfico "Gestionando el e-mail. Propuestas para una organización eficaz del correo electrónico" 21 supone un primer acercamiento profesional al tratamiento de los correos electrónicos en el ámbito privado como una suerte de archivo personal, si bien con unas necesidades específicas y diferenciadas de las que llevaban aparejadas este tipo de archivos físicos.

Más allá de las soluciones concretas aportadas en estas aproximaciones, que no conviene olvidar que se proporcionan políticas de gestión institucionales, destaca por encima de todas una cuestión: la necesidad de diseñar a priori una estrategia para la gestión documental del correo electrónico. Tal estrategia debe ajustarse a las necesidades y también debe concebirse a medio o largo plazo, esto es, no puede limitarse al acceso y organización inmediata de los correos electrónicos enviados y recibidos, más bien debe tener por objeto su acceso, organización y conservación a medio y largo plazo, al tiempo que se diseñe también un mecanismo que permita la eliminación o borrado de aquellas cosas que no se desee conservar y que, por otra parte, consumen recursos de almacenaje.

20 La Conferencia de Archiveros en las Universidades Españolas (CAU) surge en 1994, si bien no se formaliza hasta 2002, fecha en la que se integra en la Conferencia de Rectores de las Universidades Españolas (CRUE). Es posible encontrar más información sobre su trabajo, así como el resultado de éste (informes, documentos, conferencias, etc.), en su página web: <http://cau.crue.org/>, [consulta: 03/07/2016].

21 En este monográfico se aborda a través de las contribuciones de Pablo García González, Oscar Ríos Hilario y Antonio Palma Gómez el asunto de la gestión documental y la conservación de los correos electrónicos (García González, 2011; Ríos Hilario, 2011 y Palma Gómez, 2011). 
El tratamiento archivístico que estas colecciones de documentos digitales pudieran recibir está incuestionablemente supeditado a su conservación, motivo este por el que es esencial el desarrollo de herramientas y métodos de gestión que posibiliten su preservación, tanto a su contenido como en su aspecto material.

No obstante, una de las primeras cuestiones que se suscitan es la necesidad de escoger entre la ingente cantidad de documentación que se genera. Las nuevas tecnologías han llevado aparejada, y aludo a él en pasado pues se trata ya de un fenómeno asentado y conceptualizado por los investigadores, la multiplicación exponencial de la información generada y esto, en el ámbito comunicacional se ha traducido en la multiplicación exponencial del número de mensajes producidos. Mensajes estos, como se ha indicado ya, enormemente diversificados en cuanto a su forma y medios de producción.

Los documentos digitales, por otra parte, llevan implícita de alguna forma la accesibilidad, pero esto no significa en modo alguno que favorezca las condiciones para su preservación. Con frecuencia sucede que lo digital, como se indicaba anteriormente, es también efímero en cierto sentido, o, por otra parte, la tecnología no garantiza el acceso a largo plazo a la información contenida en estos documentos ni a los documentos mismos, logrando así que esta fugacidad se convierta en rasgo definitorio de este tipo de documentación. Sin embargo, hoy no solo las instituciones que son tradicionalmente custodias de la memoria colectiva, esencialmente archivos y bibliotecas, han desarrollado una cierta conciencia al respecto de la necesidad de garantizar la salvaguarda de estos documentos y la información albergada en ellos, sino que también proliferan iniciativas de carácter particular. Sirva como ejemplo la de dos artistas, Dragan Espenschied y Olia Lialina, cuyo proyecto One Terabyte of Kilobyte Age ha tratado de recuperar mucha de la información de las páginas personales que Geocities albergaba ${ }^{22}$. Sin embargo, el trabajo de estos dos artistas orbita en torno a la fragilidad de los soportes digitales, al tiempo que alerta de la pérdida de memoria que supone, en definitiva, esta pérdida de información, coadyuvada por la extinción, clausura y cierre cada vez más frecuentes de aquellos lugares en los que se alberga ya la cultura digital del presente.

La conjunción de ambas cuestiones, esto es, la fugacidad de la información y los documentos digitales y la superproducción de éstos, plantea un enorme problema de partida: la selección de aquello a lo que se destinará el esfuerzo y la labor de preservación puede que no sea una decisión de carácter voluntario y razonado, tomada por el archivero de acuerdo con el método científico que plantea la ciencia archivística como sucede con la documentación tradicional en la mayor parte de los casos, sino que dependerá de una suma de factores, algunos de ellos impuestos por la realidad tecnológica o los medios disponibles.

22 Una reseña y comentario de este proyecto se puede leer en el blog de tecnología de El País Digital, El arte en la edad del silicio (<http://blogs.elpais.com/arte-en-la-edad-silicio/2013/05/la-insoportable-levedad-de-losarchivos-digitales.html>, [consulta: 03/07/2015]) bajo el título "La insoportable levedad de los archivos digitales". El proyecto y toda la información sobre él está recopilado en la web $<$ http://contemporary-homecomputing.org/1tb/>, [consulta: 03/07/2016]. 
Las peculiaridades de los documentos susceptibles de conformar los epistolarios digitales constituyen, pues, elementos que han de condicionar necesariamente el tratamiento que se les proporcione, por lo que la secuencia tradicional (descripción, acceso y preservación) se habrá de ver consecuentemente adaptada a su realidad y sus necesidades.

Con carácter previo al tratamiento que sea de aplicación para estas colecciones documentales, los epistolarios digitales, se impone, pues, la necesidad de resolver un problema de enormes dimensiones: su conservación. No existe necesidad de aplicar ningún tipo de tratamiento a aquello que se ha perdido, y es ya un hecho cierto que enormes caudales documentales están desapareciendo en esta acertadamente denominada ya por algunos autores como "nueva Edad Media" e, incluso, "Edad Oscura"23.

El contexto informacional contemporáneo es desde hace algunos años descrito como un agujero negro en las políticas documentales, pues buena parte de la información que se está creando se está destruyendo o perdiendo irremisiblemente a un ritmo casi idéntico al de generación. Con objeto de frenar esta destrucción se articuló el programa de la UNESCO Memoria del mundo, siendo uno de los objetivos prioritarios del mismo desarrollar una conciencia mundial relativa a la vulnerabilidad del patrimonio documental digital y la necesidad de desarrollar una estrategia supranacional capaz de propiciar su salvaguarda ${ }^{24}$.

Así, pues, ya se tiene una cierta conciencia de la necesidad de evitar la desaparición del patrimonio documental y bibliográfico que se está creando en entornos digitales, si bien desde diferentes organismos nacionales e internacionales se sigue insistiendo en lo mucho que en materia de conservación queda por hacer. En lo que respecta a algunos tipos de documentos, como sucede, por ejemplo, con las páginas Web, se están ensayando ya desde hace décadas diversas fórmulas que garanticen la conservación de esta información para las generaciones futuras. Además de las iniciativas pioneras y tremendamente ambiciosas de la Library of Congress o de la Biblioteca Nacional de Australia, son ya innumerables los proyectos de conservación que hoy ya están en marcha y han madurado considerablemente desde sus planteamientos iniciales ${ }^{25}$.

23 Terry Kuny acuñó a finales de los noventa la expresión “digital Dark Ages” para hacer referencia a la época de pérdida de información que se estaba viviendo. Más allá de establecer algunas de las causas de esta irremisible pérdida, Kuny traza un paralelo entre la labor de los monjes y los monasterios medievales en la transmisión y preservación de la cultura con la misión que hoy compete a los profesionales de la información, que tienen la responsabilidad de garantizar el acceso de las generaciones futuras a la información que se está generando en el presente (Kuny, 1997: 2-3).

24 Uno de sus principales logros ha sido la redacción de la Carta UNESCO sobre la preservación del patrimonio digital y la elaboración de las ulteriores Directrices de la UNESCO para la conservación del patrimonio digital. Sin embargo, la virtud más reseñable de este proyecto ha sido la implicación de diversos organismos y asociaciones profesionales internacionales, que son las que han aportado en realidad la visión a este programa.

25 Los proyectos de conservación se articulan en torno a las principales estrategias de conservación, que son la actualización, la migración, la emulación, la preservación de la tecnología e, incluso, la arqueología digital. Para poder llevarlas a la práctica son indispensables los conjuntos o esquemas de metadatos y, dentro de estos, son singularmente significativos los metadatos de preservación (recordkeeping metadata) que no constituyen necesariamente una categoría independiente dentro de los esquemas de metadatos sino que a veces son la adición de varios tipos. Casi todas las grandes organizaciones y bibliotecas o archivos nacionales tienen grupos de trabajo orientados a la preservación y archivo digital (digital archiving) que tienen como labor 
Sin embargo, los grandes olvidados de estas políticas de conservación que se están implementando son los documentos personales, pues para ellos tampoco en el paradigma documental tradicional se desarrollaron estrategias de conservación propias. Este hecho tiene que ver, en buena medida, con el poco interés que la documentación privada ha despertado hasta épocas muy recientes y, desde el punto de vista de su integración en el patrimonio documental, la Ley del Patrimonio Histórico Español contempla que tales documentos son susceptibles de formar parte de éste si tiene más de cien años de antigüedad ${ }^{26}$, por lo que tampoco el legislador ha contribuido a fomentar su consideración como parte del patrimonio documental. La protección, pues, que le brinda la ley es ciertamente escasa, dado que no considera otra excepción a esta regla que su adquisición por una institución pública, o bien que sea legada a ella, momento éste en el que se integraría dentro del patrimonio documental por razones de titularidad o bien su declaración como tales en el caso de que "merezcan dicha consideración", pero no se establecen los criterios que puedan justificar esta consideración ${ }^{27}$.

Las felices casualidades en algunos casos, pero, sobre todo, el apego a la palabra escrita que las sociedades han demostrado a lo largo de los siglos desde la extensión de la alfabetización (Castillo, 2011: 22-23) están entre las causas de que importantes colecciones de cartas hayan llegado hasta nosotros. A pesar de la ingente cantidad de cartas que se han llegado a escribir a lo largo de los siglos, un porcentaje indeterminado pero seguramente enorme se ha destruido por diversos motivos, uno de ellos el desinterés de sus receptores tras su lectura por conservar estos testimonios (Mandingorra, 2000).

Pues bien, algo muy parecido está teniendo lugar en el presente, si bien se trata de un fenómeno acrecentado por la realidad aumentada en la que vivimos. Uno de los problemas que la migración de las relaciones epistolares al universo digital y la implantación de nuevos usos comunicativos plantea es la pérdida irremediable de importantes colecciones de misivas intercambiadas a través de, por ejemplo, el correo electrónico al tiempo que se pierde otra gran cantidad de la información creada en soportes tradicionales. Esto tiene en gran parte que ver con que la Sociedad de la Información está en cierto sentido debilitando el aprecio y valor dado a la palabra escrita. Aquello del verba volant scripta manent, muy ligado a la

prioritaria el estudio e investigación de líneas de trabajo prioritarias al respecto, el fortalecimiento de la colaboración nacional e internacional en la materia, y el desarrollo de estándares aplicables a las necesidades detectadas, así como continuar el desarrollo de los conjuntos de metadatos ya existentes. La bibliografía existente sobre la materia es abrumadora, así como los documentos de trabajo y los sitios web de estos grupos muy numerosos pero conviene, al menos hacer referencia al actualmente cerrado pero muy reseñable de OCLC y RLG (OCLC/RLG, 2002), también al proyecto PREMIS de la Library of Congress (Library of Congress, 2009), a la iniciativa de archivos abiertos (OAI) y su protocolo para la recolección de metadatos (OAI-PMH) que tiene por objeto facilitar la interoperabilidad de los repositoriosy, más recientemente, los esfuerzos llevados a cabo para la conservación de las páginas web (Web Archiving) coordinados por el Consorcio Internacional para la Preservación de Internet (IIPC, International Internet Preservation Consortium), organización que desde 2010 aúna las principales iniciativas mundiales en esta área y a la que pertenecen diversas bibliotecas nacionales, archivos y bibliotecas de investigación y universitarias.

26 Ley 16/1985, de 25 de junio, del Patrimonio Histórico Español, art. 49.

27 Ibid., art. 49.5. 
existencia de un soporte tangible para la escritura, se ha desdibujado notablemente como consecuencia de la irrupción de la tecnología en la comunicación cotidiana ${ }^{28}$.

El cambio acontecido en lo que respecta a la consideración de permanencia de la palabra escrita en el nuevo entorno informacional ha devenido en que una gran parte de esta comunicación se considere efímera y no se tenga ni siquiera la intención de buscar el modo de almacenarla. Más aún, la era digital está transformando de un modo muy profundo la esencia de la comunicación misma y está alterando muchas de las señas que le venían confiriendo su identidad desde la generalización de la escritura.

Asimismo, y de la misma manera que los estudios de los epistolarios tradicionales incluyen habitualmente el estudio de sus características físicas o materiales, también en el caso de los epistolarios digitales será necesario acercarse en el futuro al estudio de sus características tecnológicas, pues estas son la transposición de sus características físicas a la realidad de los nuevos soportes y las nuevas herramientas a través de las que se canaliza su contenido.

\section{La necesidad de una estrategia}

Como ya se ha puesto de manifiesto, se han multiplicado los problemas relacionados con la conservación de estos conjuntos documentales desde el punto de vista material, que ahora es una cuestión tecnológica. Asimismo y como ha sucedido a lo largo de la Historia, el mismo receptor de las comunicaciones será quien se encargue en un primer momento de desechar aquello que no tenga mayor trascendencia y que, por tal motivo, no requiera el esfuerzo de plantear su conservación. Sin embargo, la conservación de los correos electrónicos y de otro tipo de intercambios comunicacionales requiere un esfuerzo añadido en el ámbito virtual, pues la obsolescencia tecnológica hará preceptivo conservar los programas en los que estos mensajes fueron generados para poder tener acceso a ellos.

Este es el motivo por el que resulta también de aplicación a los correos electrónicos, agrupados en conjuntos documentales, las pautas ya admitidas y generalizadas entre la comunidad archivística para el tratamiento de los documentos digitales.

Se admite ya de forma casi universal que el creador de los documentos digitales, sean estos cuales sean, tiene un papel decisivo en su futura conservación y en la forma en la que se acceda a éstos en el futuro. Así sucede, por ejemplo, con la incorporación de conjuntos de metadatos para la conservación desde el momento

28 Las consecuencias de este cambio de mentalidad en lo que a la permanencia de la palabra escrita se han dejado sentir en aspectos muy diversos. Uno de estos aspectos tiene que ver con la "reputación digital"; recuérdense algunas crisis de reputación experimentadas por diversos personajes famosos a propósito de twitter, o el "derecho al olvido", al que tan recurrentemente se hace alusión. De esto último existe ya alguna sentencia judicial incluso (véase reseña sobre esta sentencia en El País de 25 de junio de 2013, disponible en $<$ http://sociedad.elpais.com/sociedad/2013/06/25/actualidad/1372142902_959606.html>, [consulta: 03/07/2016]). La realidad es que es en este contexto cuando la información permanece más tiempo y es más accesible para más personas y, sin embargo, es cuando menos atención se presta a su conservación y también mayor despreocupación se demuestra por las consecuencias que los mensajes emitidos pudieran acarrear. 
mismo de su creación ${ }^{29}$. También está muy admitido que el uso de estándares para la creación de los documentos es otra de las cuestiones que facilita enormemente su conservación, pero también la compatibilidad y la interoperabilidad. Esta cuestión vino a consagrarse a través de la Ley 11/2007, de 22 de junio, de acceso electrónico de los ciudadanos a los servicios públicos, que en su articulado hace referencia en varias ocasiones al uso de estándares abiertos y estándares de uso generalizado para favorecer la interoperabilidad.

Para los correos electrónicos, como objetos digitales que son, resultan de aplicación también las mismas cuestiones que preocupan de forma general: asegurar su legibilidad e inteligibilidad en el futuro, conservar su integridad y autenticidad y afrontar plazos de obsolescencia tecnológica cada vez más acortados.

Por otra parte, emulación, migración y conversión son los ejes a través de los que ya se están canalizando las estrategias de conservación para grandes conjuntos documentales. Sin embargo, implementar estos procedimientos a pequeña escala puede convertirse en una carga mayor que la del hipotético beneficio que el usuario individual pudiera percibir, siendo necesario recurrir a otras herramientas más acordes a las necesidades. Así, se están desarrollando modelos de archivo para cuentas de correo individuales, incluso modelos para la conservación de estos documentos en la nube ${ }^{30}$. Estas soluciones, no obstante, representan la pérdida del contexto tecnológico, en muchos casos, en el que se han creado e intercambiado los correos electrónicos, pudiendo perder, en consecuencia, una parte significativa de la interpretación material de los epistolarios digitales.

Lo que es bien cierto es que se precisa una estrategia que parta de la conciencia individual de la necesidad de conservar para poder acceder en el futuro a la información de relevancia que contengan los correos electrónicos, así como a los archivos adjuntos que pudieran contener. En algunos casos, como sucede con figuras especialmente representativas vinculadas, por ejemplo, a la creación literaria, la investigación u otro tipo de cuestiones, deben tener si cabe más clara esta conciencia, pues una parte sustancial de sus archivos personales estará constituida por este tipo de documentos. Así, las donaciones de archivos personales en vida de sus propietarios a instituciones culturales, que son cada vez más habituales $^{31}$, suponen la asunción de la importancia de estos conjuntos documentales y es previsible que, cada vez más, los documentos digitales constituyan una parte cada vez mayor entre aquellos.

29 Véase el artículo de Alejandro Delgado al respecto de los metadatos de conservación y su implantación en archivos (Delgado, 2005).

30 Estas soluciones individuales o personales se empiezan a ofrecer tomando como reflejo la evolución de los sistemas de archivado corporativos, pensados para grandes volúmenes de documentos, y que, en líneas generales, se presentan como sistemas de "hospedaje", hosting, o sistemas de almacenamiento en la nube, cloud computing (García Hernández: 2011).

31 Son muchísimos los ejemplos de donaciones de estas características que se pueden citar. Entre los más recientes, por ejemplo, los efectuados por Rosa Montero, Muñoz Molina o Jesús Marchamalo a la Biblioteca Nacional. Todos estos archivos forman hoy parte de la colección de archivos personales del Servicio de Manuscritos e Incunables de la Biblioteca Nacional de España. 


\section{A modo de colofón}

Las dinámicas de la comunicación han hecho, como se ha analizado, indispensable la incorporación de la tecnología disponible a los usos comunicativos, trasladando la carta tradicional al escenario digital bajo múltiples apariencias. Sin embargo, no sólo ha cambiado la forma, sino que el carácter diferido de este tipo de comunicación lo es cada vez menos. Ya se redujo considerablemente con la mejora de las comunicaciones físicas (servicios de postas primero, medios de comunicación terrestres y aéreos después), pero el salto producido en el entorno digital ha difuminado hasta casi borrar las barreras que el tiempo y el espacio imponían a las cartas.

Este fenómeno lleva asociado, asimismo, un cierto desinterés por la conservación de los testimonios de la comunicación. Del mismo modo que durante siglos las cartas han sido atesoradas por sus receptores hasta convertirse en las colecciones cuyo contenido ha revelado información enormemente significativa para el conocimiento de asuntos muy diversos, hoy apenas se repara en la posible importancia que el contenido de estos intercambios de mensajes pudiera albergar, prestándose escasa atención a la necesaria tarea de conservarlos. Por tal motivo, y como ha sucedido ya durante largo tiempo con el archivo de páginas web, se está perdiendo de forma irremisible una información que puede llegar a ser muy valiosa, si exceptuamos aquellos intercambios comunicativos que carecen de trascendencia.

Cuando a finales de la década de los 90 del siglo pasado Terry Kuny acuñaba la expresión digital Dark Ages para trazar un paralelo entre la pérdida de información que estaba teniendo lugar en el contexto digital con la irremisible pérdida que para la Historia de la Cultura supuso la Edad Media, en lo que a los documentos electrónicos susceptibles de formar parte de los archivos privados no se ha avanzado gran cosa desde entonces.

Los usuarios de las tecnologías de la comunicación en primera instancia han de desarrollar la conciencia de la importancia que puede entrañar para su propia memoria individual la conservación a largo plazo de los testimonios de sus comunicaciones personales; pero también los archivos y sus archiveros han de hacer un considerable esfuerzo para asumir el reto que se está planteando en lo que al tratamiento y conservación de estos epistolarios digitales ser refiere, pues de esta gestión depende que en el futuro sea posible acceder a la información encerrada en ellos para leer la intrahistoria de nuestros días tal y como nosotros hemos descubierto entre las líneas de muchas cartas la intrahistoria del pasado.

Es incuestionable que para que estos documentos lleguen a conservarse ha de instaurarse la conciencia de la necesidad de hacerlo. Del mismo modo que se guardaban escrupulosamente las misivas en el pasado, hoy es necesario partir de la concepción de que los correos electrónicos y otro tipo de "cartas digitales" guardan la misma información que hasta ahora se guardaba en las cartas y, en este sentido, se hace necesario fomentar la asunción de la necesidad de garantizar la conservación de aquellas que se considere que merecen este esfuerzo, pues ya no se trata sólo de buscar una "caja de galletas" en la que atesorar cartas, sino hacerlo de modo que se 
pueda acceder a su contenido en el futuro, teniendo en cuenta que la tecnología está en constante evolución y esto favorece la obsolescencia de los medios que en el momento de su generación eran adecuados para acceder a su contenido.

Por otra parte, el papel de los archivos en el tratamiento y conservación de estos conjuntos documentales se encuentra supeditada a la recepción de tales conjuntos. En el ámbito institucional o corporativo, es claro ya que se ha diagnosticado en muchos casos la necesidad de desarrollar estrategias tendentes al tratamiento integral de estos conjuntos documentales, pero en otros ámbitos, especialmente en los personales, en los que se crean los epistolarios que aquí se abordan, conviene intervenir para alcanzar el convencimiento de lo perentorio de asegurar el acceso y la conservación de estos documentos a largo plazo.

\section{Referencias bibliográficas}

Arcos Pereira, T. (2008). De Cicerón a Erasmo: La configuración de la epistolografía como género literario. Boletín Millares Carlo, nº 27, 347-400.

Cantavella, J. (1989). Epistolarios de escritores: escritura y persona. Cuadernos hispanoamericanos, $\mathrm{n}^{\circ}$ 463, 127-137.

Castells, M. (2009). Comunicación y poder. Madrid: Alianza Editorial.

Castillo Gómez, A. (2002). Del tratado a la práctica. La escritura epistolar en los siglos XVI y XVII, en Congreso Internacional de Historia de la Cultura Escrita, 2 vols. Alcalá de Henares, Universidad de Alcalá de Henares, vol. I, 266-290.

Castillo Gómez, A. (2011). Me alegraré que al recibo de ésta... Cuatrocientos años de prácticas epistolares (siglos XVI a XIX). Manuscrits, $\mathrm{n}^{\circ}$ 29, 19-50.

CAU-Grupo de trabajo de documentos electrónicos. Propuesta de recomendaciones para la gestión y conservación del correo electrónico en las universidades españolas $<$ http://cau.crue.org/export/sites/Cau/Quehacemos/gruposdetrabajo/document oselectronicos/recomendaciones_correo.pdf $>$ [Consulta: 05/07/2016].

Cerdá Díaz, J. (2013). Después de la Ley 11/2007. Archivos y archiveros en la Administración Electrónica. Anales de Documentación, 16 (1), 1-21.

Cortés Ibáñez, E. (2010). El epistolario, espejo de la intrahistoria, en Cortés Ibáñez, E., coord., Zenobia Camprubí y la Edad de Plata de la cultura española. Sevilla: Universidad Internacional de Andalucía, 266-290.

Delgado Gómez, A. (2005). Archivos y metadatos de conservación: estado del arte y propuesta metodológica. Scire, 11 (1), 83-101.

Elías, C. (2009). La "cultura convergente" y la filosofía Web 2.0 en la reformulación de la comunicación científica en la era del ciberperiodismo. ARBOR Ciencia, pensamiento y cultura, $\mathrm{n}^{\mathrm{o}} 737,623-634$.

Feijoo Casado, A. M. (2009). La e-administración el paso de la gestión tradicional a la gestión electrónica. Revista General de Información y Documentación, n 19, 161-171.

Figuerola, M. del C. (2002). Pensar la historia por carta: el epistolario de Jean-Richard Bloch y Marcel Martinet, en Parra Alba, M. et al., Literatura epistolar: correspondències (s. XIX-XX). Lleida: Editions Universitat de Lleida, 197-214.

Gallego Cuiñas, A. y Martínez, E. (eds.) (2013). Queridos todos. El intercambio epistolar entre escritores hispanoamericanos y españoles del siglo XX. Bruselas: Peter Lang.

García Hernández, P. (2011). E-mail Archiving: del modelo On-premise al Cloud Computing. Archivamos, no 82, 26-28. 
González García, J. M. (2014). El proyecto Epístola: edición digital de los epistolarios de la Edad de Plata. Humanidades digitales: desafíos, logros y perspectivas de futuro. Janus, Anexo 1, 197-208.

Hernández Olivera, L. (2011). La paranoia de conservar. Archivamos, nº 82, 34-35.

ISO/TR 15801:2004: recomendaciones para la veracidad y fiabilidad de información almacenada electrónicamente.

ISO/TR 18492:2005: conservación a largo plazo de información electrónica basada en documentos.

ISO/NP 26102: requisitos para la conservación a largo plazo de los documentos electrónicos.

Jacobs, J. A. et al. (2005). Government Information in the Digital Age: The Once and Future Federal Depository Library Program. Journal of Academic Librarianship, 31 (3), 198-208.

Knott, M. L.; Heredia, D., (eds.) (2010). Der Briefwechsel.Hannah Arend-Gershom Scholem. Berlín: Suhrkamp.

Kuny, T. (1998). The digital dark ages? Challenges in the preservation of electronic information. Internacional Preservation News, $\mathrm{n}^{\mathrm{o}} 17$.

Library of Congress Network Development and MARC Standards Office (2009). Entender PREMIS. <http://www.mecd.gob.es/cultura-mecd/areas-cultura/bibliotecas/mc/premis/ capitulos.html> [Consulta: 12/12/2016].

López García, P. I. (2007). Julio Camba a través de su epistolario. Anales de Literatura Española, no 19, 137-160.

Mandingorra, M. L. (2000). Conservar las escrituras privadas, configurar las identidades. Valencia: Universidad de Valencia.

Marín, M. et al (2009). Los epistolarios de Julián Ribera Tarragó y Miguel Asín Palacios. Introducción, catálogo e índices. Madrid: Consejo Superior de Investigaciones Científicas.

Martín Abad, J. et al., (coord.) (2006). Seminario de archivos personales. Madrid: Biblioteca Nacional-Ministerio de Cultura.

Martín Baños, P. (2009). El arte epistolar en el Renacimiento Europeo (1400-1600). Bilbao: Universidad de Deusto.

Mestre Sanchís, A. (2000). La carta, fuente de conocimiento histórico. Revista de Historia Moderna, $\mathrm{n}^{\mathrm{o}}$ 18, 13-26.

National Digital Information Infrastructure and Preservation Program (2013). Perspectives on Personal Digital Archiving: Library of Congress. $<$ http://www.digitalpreservation.gov/documents/ebookpdf_march18.pdf $>$ [Consulta $12 / 12 / 2016]$.

OCLC/RLG Working Group on Preservation Metadata (2002). Preservation Metadata and the OAIS Information Model. A Metadata Framework to Support the Preservation of Digital Objects. <http://www.oclc.org/content/dam/research/ activities/pmwg/pm_framework.pdf $>$ [Consulta: 12/12/2016].

Palma Gómez, A. (2011). Conservando el e-mail: más allá de la preservación digital. Archivamos, $\mathrm{n}^{\circ}$ 82, 3-33.

Plummer, K. (1989). Los documentos personales. Introducción a los problemas y la bibliografía del método humanista. Madrid: Siglo XXI.

Pons Alós, V. (1996). Los archivos familiares: realidad y perspectiva desde la óptica del historiador de los archivos, en Blasco Martínez, R. M., (ed.,) Los archivos familiares en España. Estado de la cuestión. Santander: Asociación para la defensa del patrimonio bibliográfico y documental de Cantabria, 43-94. 
Ríos Hilario, O. (2011). Fin de año, un buen momento para archivar nuestro correo electrónico: diseñar una estrategia y ser metódico serán nuestros mejores aliados. Archivamos, $\mathrm{n}^{\circ}$ 82, 29-31.

Rodríguez de las Heras, A. (2004). Editorial: La migración digital. TELOS. Cuadernos de comunicación e innovación, Octubre-Diciembre, $\mathrm{n}^{\mathrm{o}}$ 61. Segunda época. $<$ http://sociedadinformacion.fundacion.telefonica.com/telos/editorial.asp@rev=61.htm> [Consulta: 9/09/2016].

Rubio Jiménez, J.; Deaño Gamallo, A. (2011). El camino de las letras. Epistolarios inéditos de Rafael Altamira y José Martínez Ruíz (Azorín) con Leopoldo Alas (Clarín). Alicante: Universidad de Alicante.

Salinas, P. (1983). Defensa de la carta misiva y de la correspondencia epistolar. Ensayos completos, 2 (II). Madrid: Taurus, 232-233.

Salmon, P. (1978). Historia y crítica. Introducción a la metodología histórica. Barcelona: Teide.

Salvador Benítez, A.; Ruíz Rodríguez, A. (2011). Innovación y nuevas tecnologías para los archivos personales. De la investigación a la difusión cultural. V Jornadas Archivo y Memoria. Extraordinarios y fuera de serie: formación, conservación y gestión de archivos personales, Madrid: Museo del Ferrocarril. $<\mathrm{http}: / /$ www.archivoymemoria.com/jornada_05/comunicaciones/5J_Com_31_Salvador _web.pdf> [Consulta 09/07/2016]. 